\title{
Diagnostically Challenging Epithelial Odontogenic Tumors: A Selective Review of 7 Jawbone Lesions
}

\author{
Fumio Ide $\cdot$ Kenji Mishima $\cdot$ Ichiro Saito $\cdot$ \\ Kaoru Kusama
}

Received: 3 December 2008/ Accepted: 16 January 2009/Published online: 20 February 2009

(C) Humana 2009

\begin{abstract}
Considerable variation in the clinicopathologic presentation of epithelial odontogenic tumors can sometimes be confusing and increase the chance of misdiagnosis. Seven diagnostically challenging jawbone lesions are described. There were 2 cases of mistaken identity in our ameloblastoma file. One unicystic type, initially diagnosed and treated as a lateral periodontal cyst, showed destructive recurrence 6 years postoperatively. The other globulomaxillary lesion was managed under the erroneous diagnosis of adenomatoid odontogenic tumor and recurred 4 times over an 11-year period. This tumor was found in retrospect to be consistent with an adenoid ameloblastoma with dentinoid. The diagnosis of cystic squamous odontogenic tumor (SOT) occurring as a radicular lesion of an impacted lower third molar was one of exclusion. Of two unsuspected keratocystic odontogenic tumors, one depicted deceptive features of pericoronitis, while the other case has long been in our files with the diagnosis of globulomaxillary SOT. Two cases of primary intraosseous squamous cell carcinoma appeared benign clinically and exhibited unexpected findings; an impacted third molar began to erupt in association with the growth of carcinoma and another periradicular carcinoma showed dentinoid formation. Cases selectively reviewed in this article present challenging problems which require clinical
\end{abstract}

F. Ide $(\bowtie) \cdot$ K. Mishima $\cdot$ I. Saito

Department of Pathology, Tsurumi University School of Dental

Medicine, 2-1-3 Tsurumi, Tsurumi-ku, Yokohama 230-8501,

Japan

e-mail: ide-f@tsurumi-u.ac.jp

F. Ide $\cdot$ K. Kusama

Division of Pathology, Department of Diagnostic and

Therapeutic Sciences, Meikai University School of Dentistry,

Sakado, Saitama, Japan and radiographic correlation to avoid potential diagnostic pitfalls.

Keywords Clinicopathologic correlation .

Diagnostic pitfall · Epithelial odontogenic tumor .

Jawbone

\section{Introduction}

The differential diagnoses of radiolucencies that occur in the maxilla and mandible include a broad spectrum of cysts and tumors of odontogenic and non-odontogenic origin. Many can be diagnosed accurately based on the distinctive clinical, radiographic and histopathologic aspects [1]. However, epithelial odontogenic tumors that present a diagnostic dilemma are encountered on occasion. In such problematic lesions, misdiagnosis often has serious implications for the patient.

During our continuous work on odontogenic tumors [2-4], we are again impressed with the importance of the correct diagnosis. The aim of this report is to present seven diagnostically challenging lesions in the jawbone with unusual clinical appearances and rare histologic features; some which were mistakenly diagnosed as non-neoplastic.

\section{Report of Cases}

Unicystic Ameloblastoma

A 30-year-old man was referred for evaluation of a small, interradicular radiolucency between the lateral incisor and canine of the left mandible (Fig. 1a). Six years postoperatively, the patient returned with a large multilocular 
Fig. 1 Unicystic

ameloblastoma. a Periapical radiograph at time of first surgery, $\mathbf{b}$ and $\mathbf{c}$ six-year postoperative periapical radiographs, d primary cyst lined with thin, non-keratinizing squamous epithelium,

e ameloblastoma lining of recurrent cyst (HematoxylinEosin-d $\times 400$, e $\times 200$ ),

f calretinin expression ( $\mathrm{ABC}$ method, $\times 200$ )
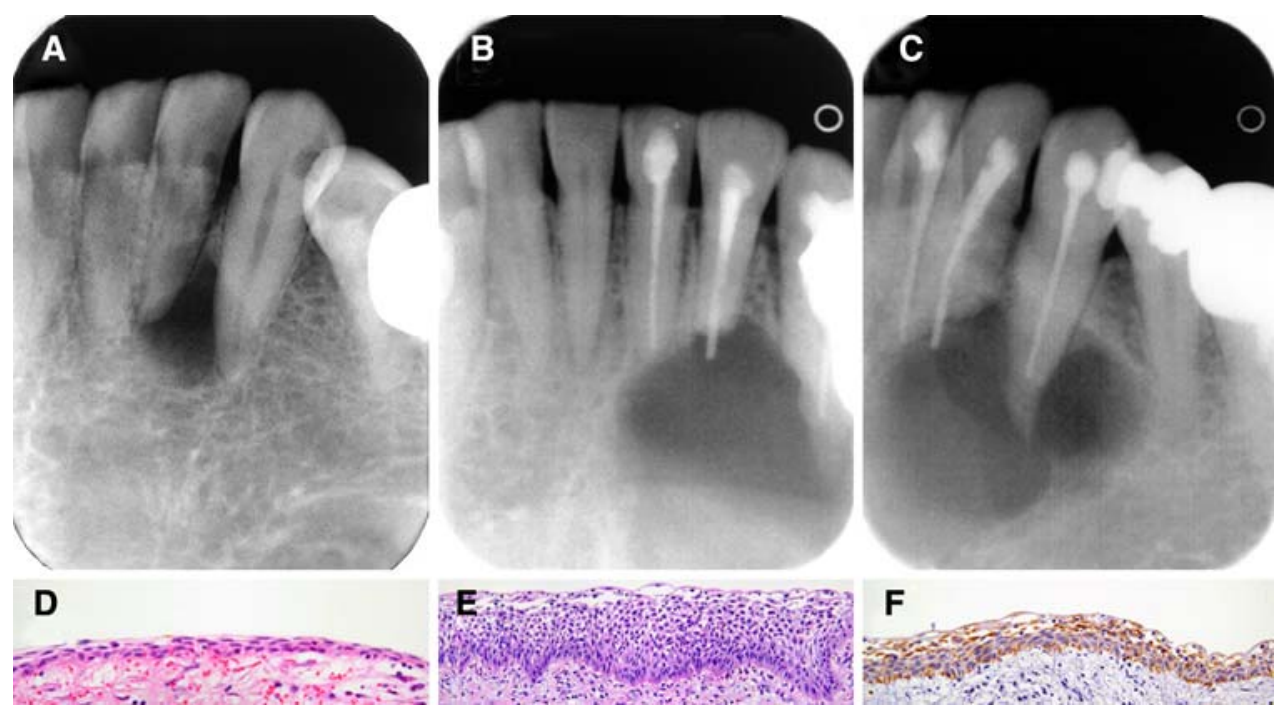

radiolucency causing root resorption (Fig. 1b, c). Microscopic findings of the primary lesion, i.e., thin-walled cyst lined by flattened, non-keratinizing squamous epithelium, were compatible with the clinically presumed diagnosis of lateral periodontal cyst (Fig. 1d). The recurrent cyst however revealed features diagnostic of unicystic ameloblastoma, luminal type (Fig. 1e). By immunohistochemistry, focal but intense reactivity for calretinin was evident in the lining epithelium (Fig. 1f). The patient is free from recurrence 8 years after marginal resection.

\section{Adenoid Ameloblastoma with Dentinoid}

In June of 1988, a 44-year-old man presented with a heart-shaped, unilocular radiolucency in the left globulomaxillary area involving the apex of the central incisor (Fig. 2a). With a suspicion of odontogenic cyst, enucleation was done and the histologic diagnosis of adenomatoid odontogenic tumor (AOT) was made (Fig. 2b). In November of 1990, the patient re-appeared with an apical radiolucent lesion in the incisor area
Fig. 2 Adenoid ameloblastoma with dentinoid. a Periapical radiograph taken in 1988, b primary tumor (1988) showing adenoid spaces and dentinoid, c periapical radiograph (2nd recurrence) taken in 1995 , d periapical radiograph (3rd recurrence) taken in 1998, e fourth recurrent (1999) tumor. Asterisk (*) showing sinus cavity, $\mathbf{f}$ typical feature of adenoid ameloblastoma with dentinoid (Hematoxylin-Eosin-b $\times 400$, e and $\mathbf{f} \times 100$ )
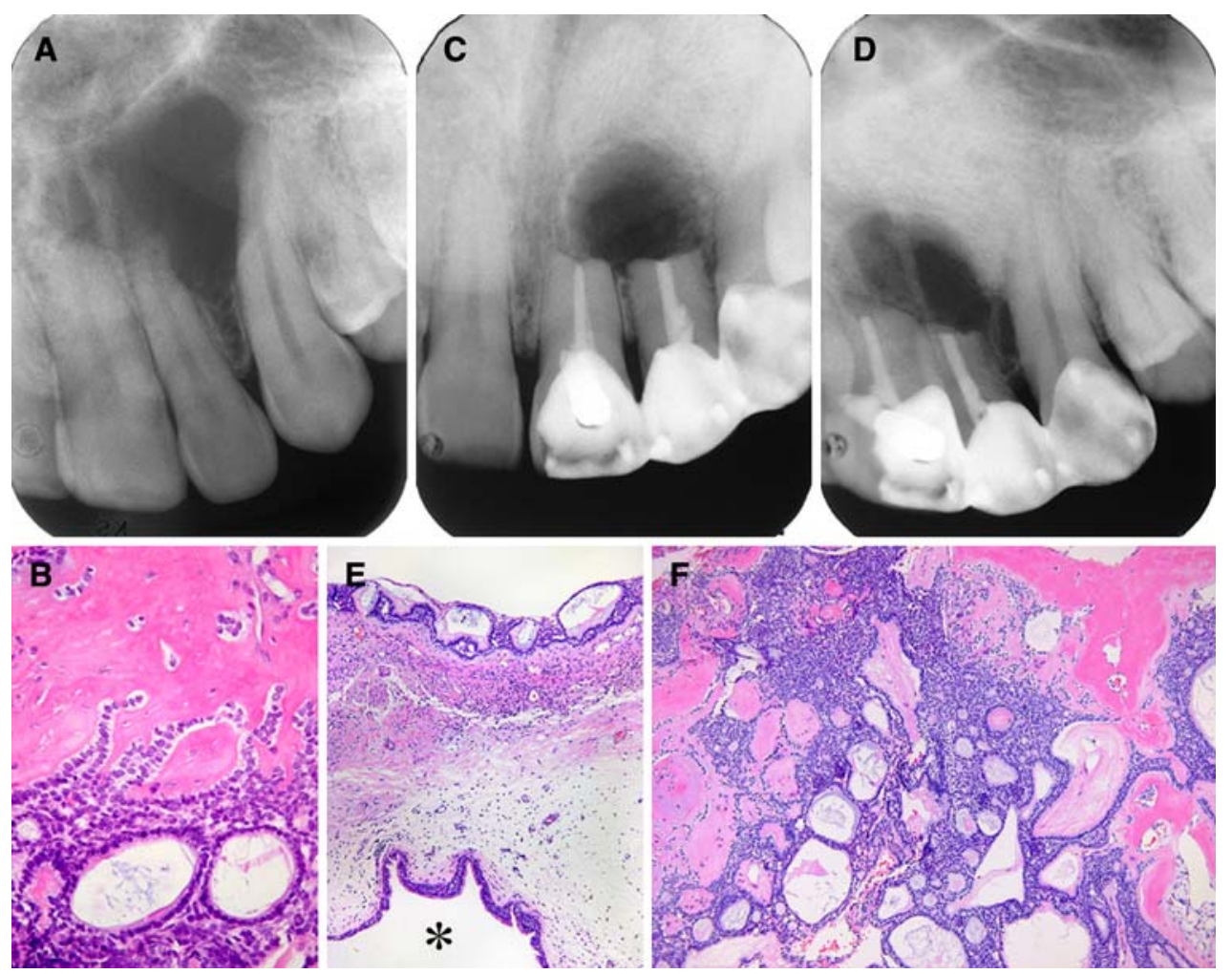
(Fig. 2c). The second biopsy was also diagnosed as AOT, recurrent. During follow-up, recurrences were noted in February of 1995 (Fig. 2d) and in April of 1998 and again reported to be AOT. In November of 1999, partial maxillectomy was performed, because of the 4th recurrence involving the maxillary sinus (Fig. 2e). Both 1998 and 1999 tumors showed intense immunoreactivity for calretinin. We agree, at least for the present, with the previous reports that the term adenoid ameloblastoma with dentinoid was appropriate (Fig. 2f). No recurrence is evident thereafter.

\section{Cystic Squamous Odontogenic Tumor}

During routine dental treatment, a well-defined, unilocular radiolucency enclosing the root of a horizontally impacted right lower third molar was found in a 46-year-old woman (Fig. 3a). A solid mass was excised along with the tooth. On microscopic examination, there were interconnected budding islands of bland squamous epithelium reminiscent of pseudoepitheliomatous hyperplasia, in addition to large cystic spaces containing desquamated keratin (Fig. 3b, c). The cyst lining had neither basal palisading nor corrugated parakeratin layer and immunostaining for Bcl-2 was negative. After a search of the relevant literature, the most likely diagnosis at this time was cystic squamous odontogenic tumor. A few tumor nests were found in the resection margins, but there has been no sign of recurrence in the ensuing 3 years.
Keratocystic Odontogenic Tumor

Case 1

The patient was a 39-year-old man who had several episodes of pericoronitis related to a horizontally impacted left lower third molar. During the past 2 years, the lesion was repeatedly incised, drained and treated with antibiotics. Radiographically, osteolytic changes extending to the root apices thought to be due to the pericoronal infection was noted (Fig. 4a). Histologically, fragments of inflamed tissue below the tooth were lined with the non-keratinizing, spongiotic squamous epithelium (Fig. 4b) and only one area had diagnostic features of keratocystic odontogenic tumor (Fig. 4c). Extraction wound was subsequently curetted, but no residual tumor remained. At 1 year follow-up there is no evidence of recurrence.

\section{Case 2}

A 44-year-old man presented with a unilocular, radiolucency with ill-defined margins in the left globulomaxillary area (Fig. 5a). Aspiration yielded no fluid. Under the clinical diagnosis of odontogenic tumor, en block excision was done. Microscopically, an unencapsulated fibrous mass consisted of solid islands of mature squamous epithelium (Fig. 5b). Larger nests displayed thin parakeratinized lining with central slits, but there was no cyst formation. In view of the characteristic budding of basal layer (Fig. 5c) and its
Fig. 3 Cystic squamous odontogenic tumor. a Panoramic radiograph, $\mathbf{b}$ and $\mathbf{c}$ solid-cystic proliferation of mature squamous epithelium (Hematoxylin-Eosin, $\times 40$ )
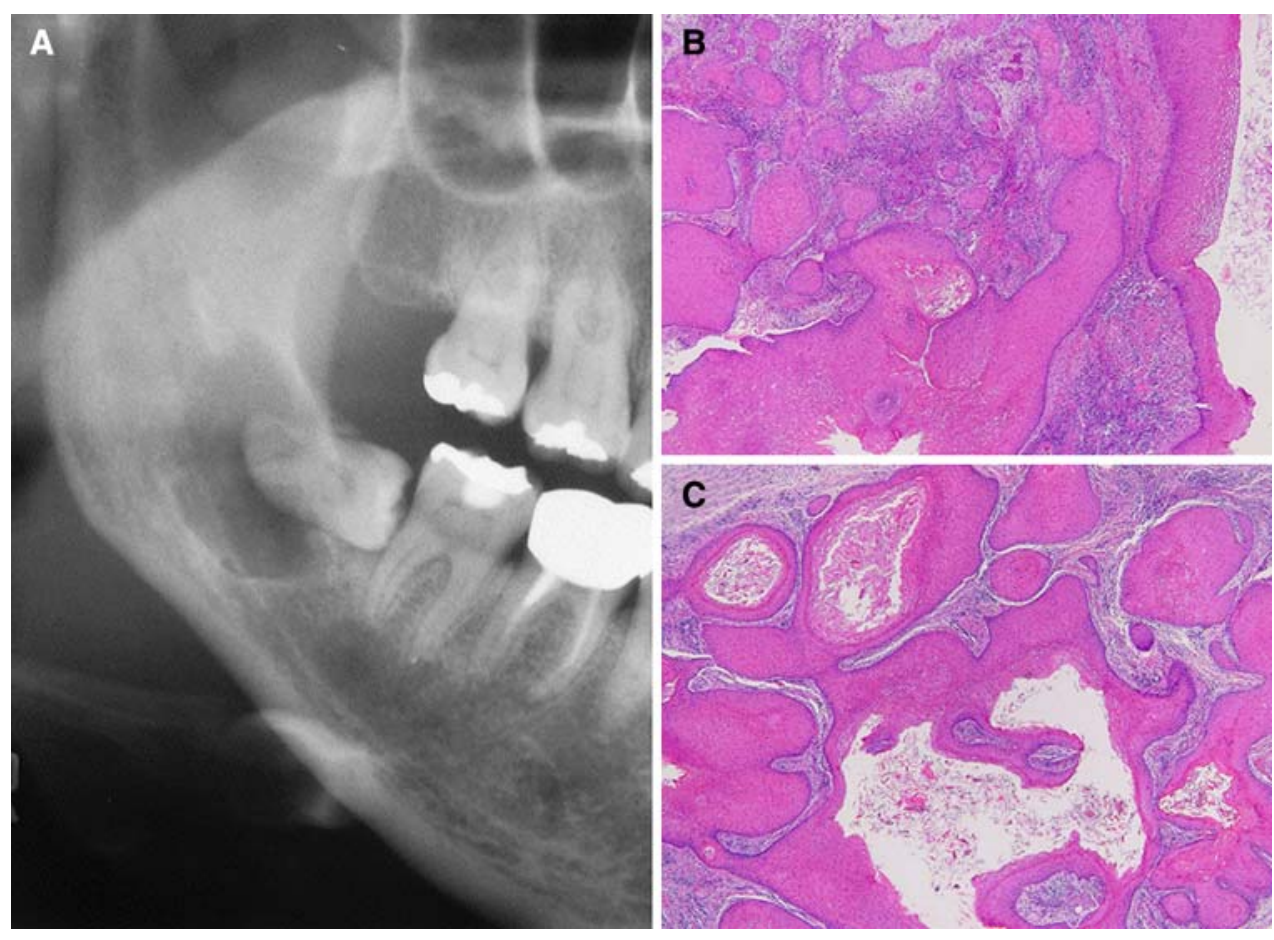
Fig. 4 Keratocystic odontogenic tumor. a Panoramic radiograph, b non-descript cyst lining with elongated rete pegs, $\mathbf{c}$ typical feature of keratocystic odontogenic tumor (Hematoxylin-Eosin-b $\times 100$, c $\times 200$ )
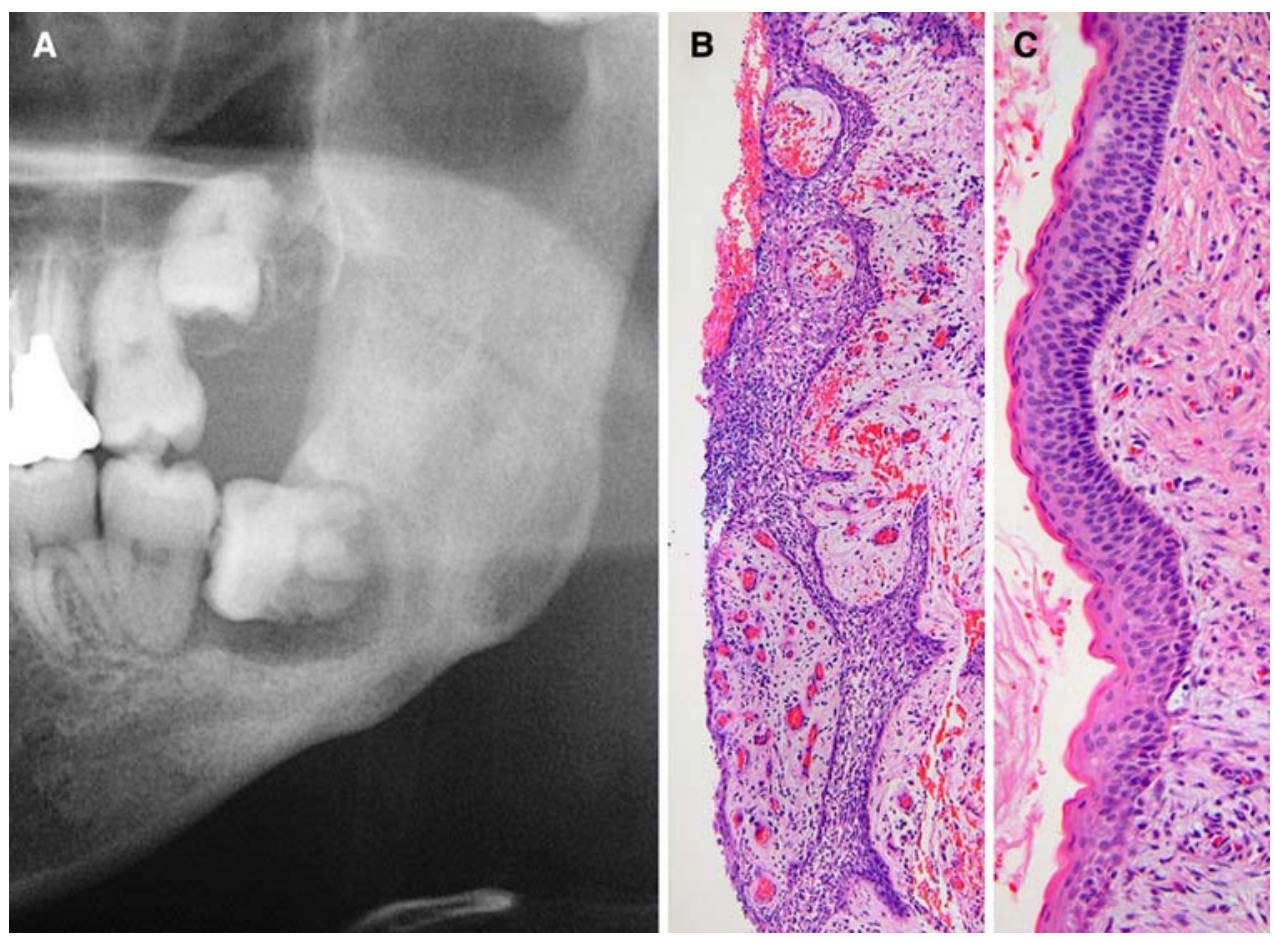

Bcl-2 immunoreactivity (Fig. 5d), the original diagnosis of squamous odontogenic tumor was revised to keratocystic odontogenic tumor of solid variant. After 3 years with no recurrence, the patient was lost to follow-up.

\section{Primary Intraosseous Squamous Cell Carcinoma}

\section{Case 1}

The patient, a 65-year-old woman, complained of a white surface speckling on the left retromolar alveolar mucosa. There was no significant radiographic change around a horizontally impacted third molar (Fig. 6a). Within 2 years, she became aware of an eruption of the tooth. Radiographically, periradicular rarefaction with an illdefined inferior margin extended deeply to the level of mandibular canal (Fig. 6b). Soft-tissues associated with the extracted molar revealed microscopic features of a welldifferentiated squamous cell carcinoma (Fig. 6c). Tumor cells were mostly immunopositive for $\mathrm{Ki}-67$ and p53 (Fig. 6d). Because the specimen was removed in piecemeal fashion, transition from pericoronal follicular or gingival sulcular epithelium to carcinoma was not observed. The patient was subsequently referred to another hospital for additional treatment.

\section{Case 2}

A 47-year-old woman related a 2-year history of a 2-cm mass on the left lower lingual gingiva. Surrounding the roots of the second premolar and first molar was a $1.5-\mathrm{cm}$, unilocular radiolucency with sclerotic inferior borders (Fig. 7a). A superficial biopsy revealed clear cell carcinoma of uncertain origin and mandibular resection was performed with cervical lymph node dissection. Histologically, small round islands and double stranded cords of basaloid tumor cells reminiscent of Malassez' epithelial rests were seen diffusely infiltrating the cancellous bone (Fig. 7b). Pleomorphism was minimal and mitoses were rare. On the superficial aspect of the resected specimen, the carcinoma fused with the gingival epithelium and focally contained duct-like spaces (Fig. 7c). Mucin-negative clear cells were restricted to this area (Fig. 7d). The most remarkable feature in the deeper portion was juxtaepithelial deposition of dentinoid (Fig. 7e). Excised lymph nodes were negative for metastasis. The lesion was most likely considered to be a primary intraosseous odontogenic carcinoma with dentinoid. At 6-year follow-up, no recurrence is noted.

\section{Discussion}

Unicystic Ameloblastoma (UA)

The clinical and radiographic aspects of UA are not specific and can be seen in odontogenic cysts $[1,3]$. In these circumstances, identification of this frequently underdiagnosed cystic tumor often comes from after recurrence [58]. Histologically, UA represents a unilocular cyst that has 
Fig. 5 Keratocystic odontogenic tumor. a Periapical radiograph, $\mathbf{b}$ solid islands of bland squamous epithelium, c basal cell budding (Hematoxylin-Eosin-b $\times 100$, c $\times 200$ ), d Bcl-2 expression (ABC method, $\times 200$ )
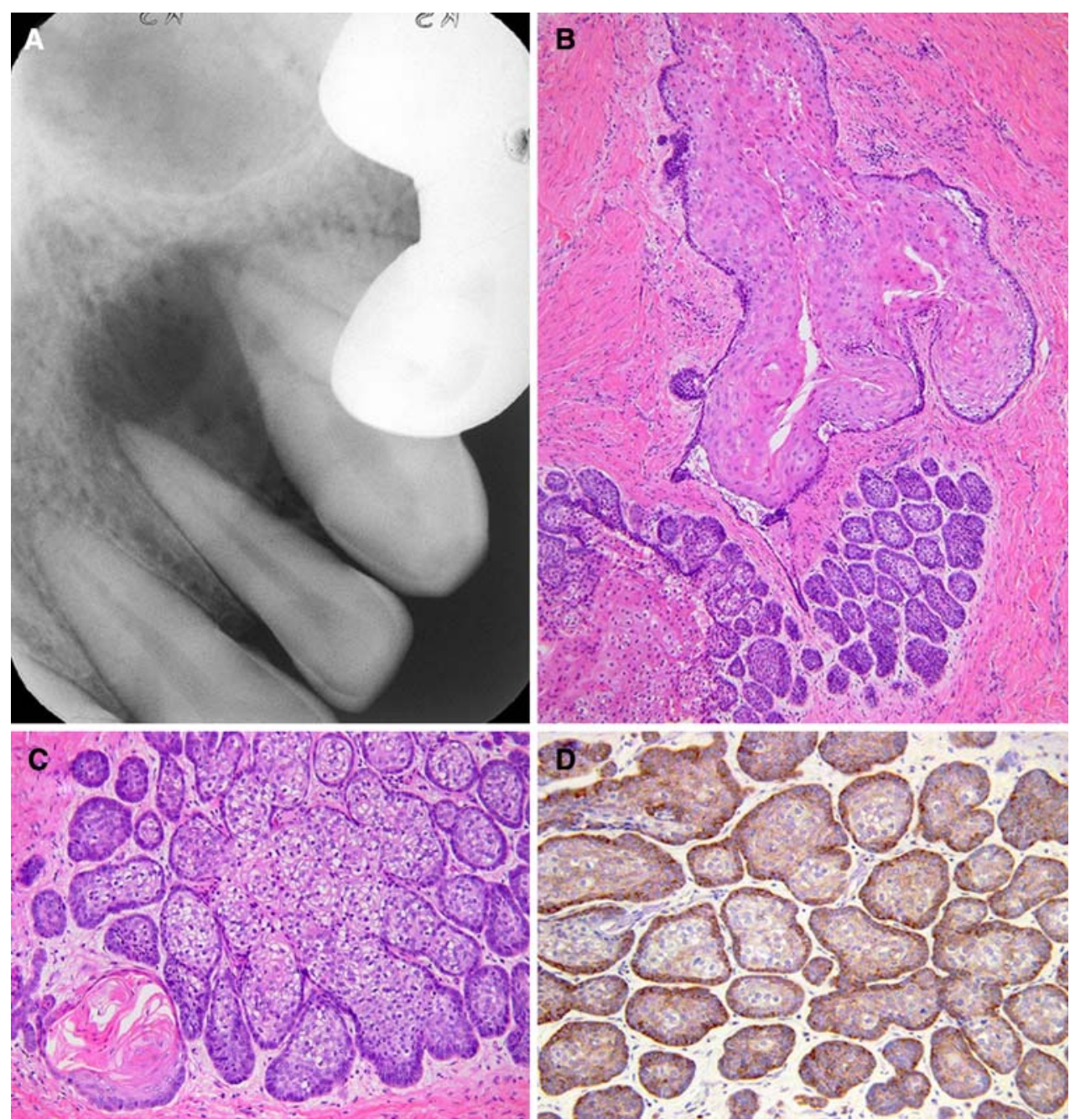

the ameloblastomatous lining with or without intraluminal and/or intramural tumor nodules [1]. However, the cyst lining of UA often lacks any feature indicative of ameloblastoma as shown in our primary lesion. In such enigmatic cases, the entire cyst should be examined through sectioning at different levels. Immunoreactivity for calretinin in the lining epithelium also gives weight to a consideration of UA [9]. From a clinical view, discrimination between UA and simple cyst is important, because of significant differences in treatment and prognosis.

\section{Adenoid Ameloblastoma with Dentinoid (AAD)}

The major remaining gap in our current knowledge of adenomatoid odontogenic tumor (AOT) includes its recurrence potential [10, 11]. Among more than 1,082 cases reported [11], there were only two publications of unequivocal AOT with recurrence [12, 13]. The 2004 literature review concluded that the reportedly recurrent AOT are almost certainly AAD [10, 14]. Although the diagnostic nosologic problem remains, the term $\mathrm{AAD}$ is applied to a rare plexiform ameloblastoma with microscopic features of AOT including duct-like structures and dentinoid deposition [10]. As shown in the present and previous cases [15], the final diagnosis of AAD was made only in retrospect, after multiple recurrences. It is imperative to understand that AAD is actually an ameloblastoma with propensity for infiltration and recurrence. Clinical and pathologic correlation is important to avoid misdiagnosis. In brief, AAD contrasts with AOT by tending to occur in an older age group and to appear as an illdefined, extrafollicular radiolucency and encapsulation is less apparent in AAD [14-16]. Good examples of this dilemma have occasionally been reported [17-19]. Microscopically, immunopositivity for calretinin may be a rationale for the ameloblastoma nature [9, 20], as evident in our AAD. The surgical pathologists should keep AAD in mind as a new diagnostic pitfall of AOT [10].

\section{Cystic Squamous Odontogenic Tumor (SOT)}

It is our opinion that the basic histomorphology of the present tumor is similar, if not identical, to that of cystic 
Fig. 6 Primary intraosseous squamous cell carcinoma. a Panoramic radiograph taken in 2006, b panoramic radiograph (2008) showing eruptive movement of third molar with osteolytic change, $\mathbf{c}$ welldifferentiated squamous cell carcinoma (Hematoxylin-Eosin, $\times 200$ ), d p53 overexpression $($ ABC method, $\times 200)$
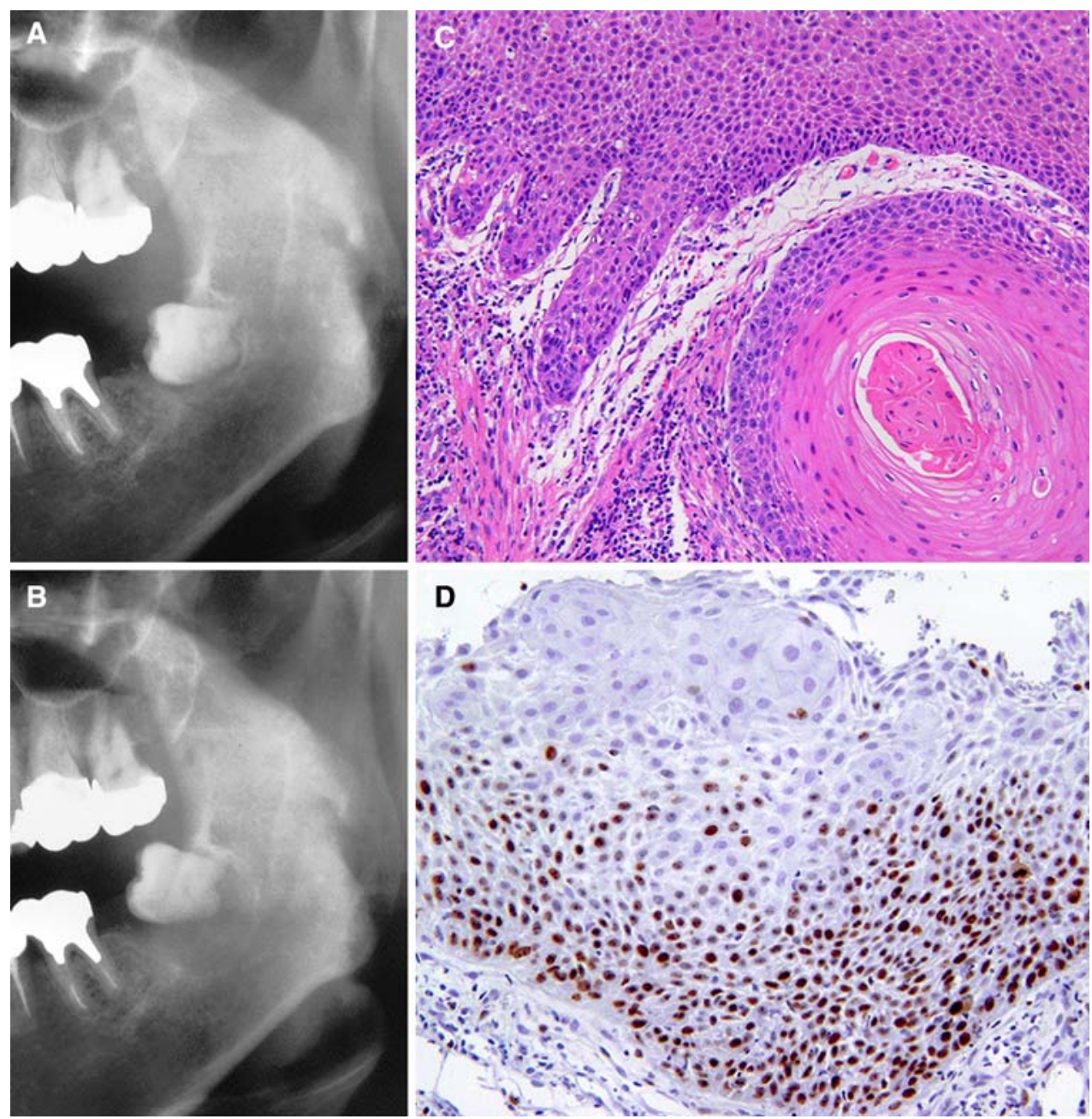

SOT [21, 22]. Whether or not an entity of cystic SOT is accepted, these cases appear to be a unique combination of large keratinizing cysts and solid squamous islands. It is likely that pure solid and solid-cystic tumors comprise a group of SOT. Of importance, the latter SOT should not lead to the diagnosis of non-neoplastic, mural SOT-like proliferations seen in several types of odontogenic cysts [1, 21]. Microscopically there can be difficulty discriminating a biopsy of SOT, from pseudoepitheliomatous hyperplasia or a keratoacanthoma-like lesion [23-26]; however, such reactive lesions are present primarily as an extraosseous gingival condition in adolescence [24-26]. Our current case which presented as a radicular lesion provides some credence to the view that SOT may arise from the rests of Malassez [2, 21]. Although rare, SOT in a pericoronal setting favors a follicular epithelial origin [27-30], with an embedded tooth totally encircled by a radiolucency in the reported adult cases [28, 29]. The radiolucent area of pediatric SOT associated with an unerupted canine also shows the involvement of the roots of neighboring teeth
$[27,30]$. It is best to consider that pericoronal SOT could still have origin from the rests of Malassez.

Keratocystic Odontogenic Tumor (KCOT)

We are unable to find any report on KCOT clinically indistinguishable from common pericoronitis. In our case 1 , a semicircular area of rarefaction below a horizontally impacted third molar was the only radiographic sign and inflammation also obscured the specific histology of KCOT. Because excised tissues were not submitted for microscopic examination, the underlying KCOT escaped early diagnosis until the lesion showed a destructive clinical course.

Given that microscopic appearance of KCOT, be cystic or solid, is pathognomonic $[1,4,31,32]$, the original diagnosis of SOT in our case 2 is an avoidable error. As shown, Bcl-2 immunoexpression may serve as a clue to the KCOT phenotype of intraosseous squamous epithelial lesions [4]. Very important from a practical view is the 
Fig. 7 Primary intraosseous squamous cell carcinoma. a Periapical radiograph, b basaloid tumor occupying cancellous space, $\mathbf{c}$ fusion of carcinoma with gingival epithelium. Note focal duct-like structures, $\mathbf{d}$ clear cell population, e dentinoid deposition (HematoxylinEosin-b and $\mathbf{c} \times 100, \mathbf{d} \times 400$, e $\times 200$ )
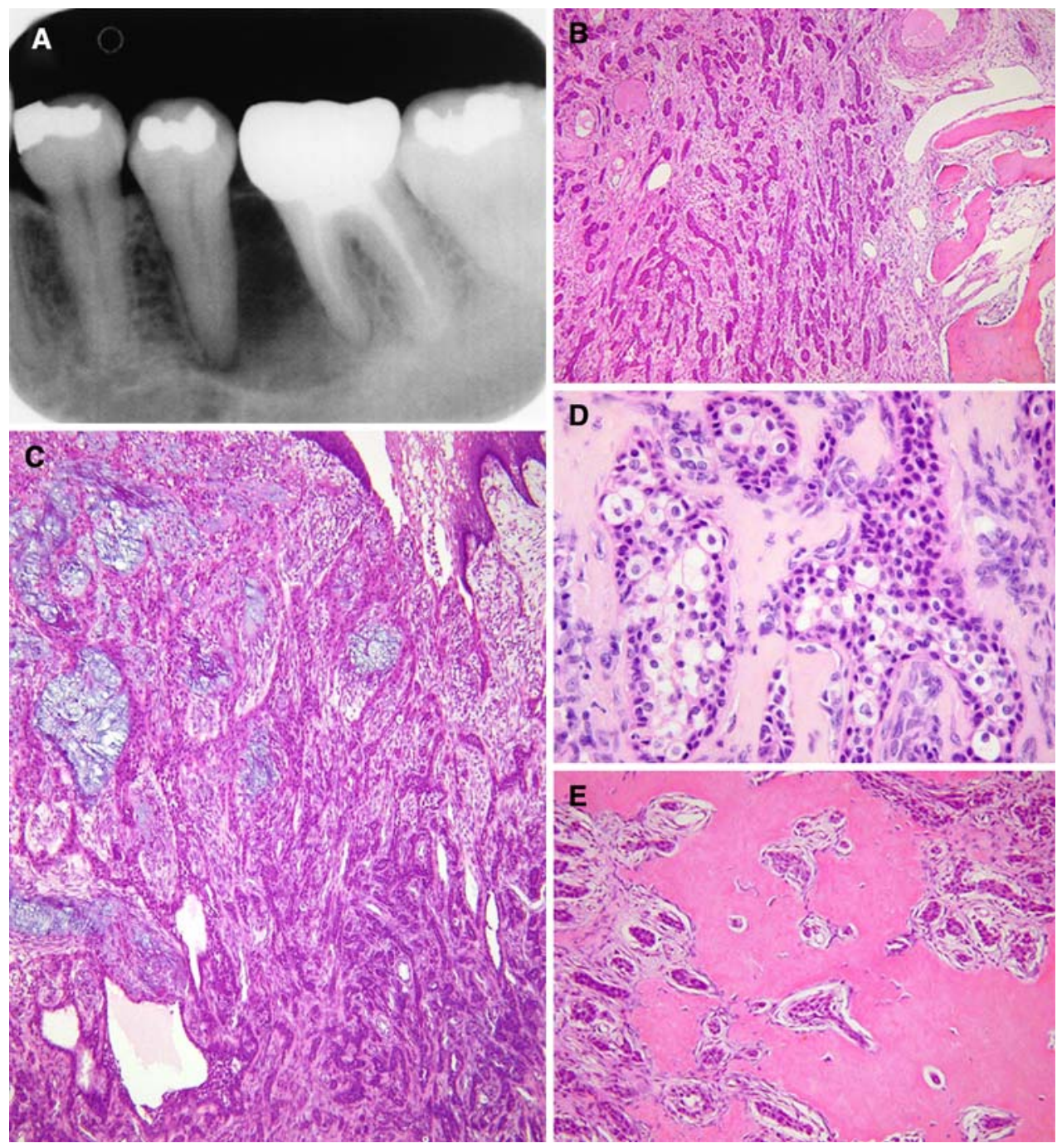

distinction between SOT and solid KCOT, because of differences in clinical behavior [33]. Only a few cases have been published [31, 32], thus precluding any meaningful conclusion that a solid variant of KCOT exhibits a greater potential for aggressive growth and recurrence compared with its classic cystic form. It is interesting to note that microscopic similarities, including overlap with KCOT, have also been observed in keratoameloblastomas [34]. To date, the issue of whether keratoameloblastoma with KCOT-like features is truly an ameloblastoma or whether it represents a histologic variant of solid KCOT remains debatable [31, 34].

\section{Primary Intraosseous Squamous Cell Carcinoma (PIOSCC)}

There have been reports of PIOSCC camouflaged as benign reactive conditions associated with a horizontally impacted lower third molar [35-38]. These incipient tumors were mostly interpreted as a carcinoma ex dentigerous cyst [36, 38], but radiolucency associated with the root part of involved tooth was the principal finding in some PIOSCC including our case $1[35,37]$. It is thus probable that the rests of Malassez may be an additional histogenetic source [37]. Nevertheless, careful consideration should be given to the sulcular epithelial origin, because of the soft-tissue impaction of the carcinoma-associated tooth [37, 38].

There are two alternatives to explain the origin of our case 2. The first possibility is that clear cell carcinoma of the minor salivary gland invaded the periradicular bone and transformed into dentinoid-forming basaloid tumor in a central location. The second possibility is that primary intraosseous odontogenic carcinoma perforated the lingual cortical plate and grew in the gingiva. Based on the clinical and pathologic correlation, the second alternative is considered the most likely. Our tumor lacks mature squamous phenotype and shares features with the recently described sclerosing odontogenic carcinoma [39]. According to the 
2005 WHO classification [1], we reluctantly use the term PIOSCC despite this fact. Significant amounts of dentinoid deposition are exceptionally rare in PIOSCC [40, 41]; however, this is a fortuitous microscopic finding without any diagnostic or prognostic significance.

In summary, clinical impressions and radiographic appearance are indispensable for the surgical pathologists who diagnose challenging jawbone lesions. Although a small number of heterogeneous cases, the results of this pathology-oriented study will, in turn, aid the head and neck surgeons in the clinical diagnosis for some of commonly misinterpreted odontogenic entities.

\section{References}

1. Slootweg PJ. Lesions of the jaws. Histopathology. 2008. doi: 10.1111/j.1365-2559.2008.03097.x.

2. Ide $\mathrm{F}$, Obara $\mathrm{K}$, Yamada $\mathrm{H}$, et al. Hamartomatous proliferations of odontogenic epithelium within the jaws: a potential histogenetic source of intraosseous epithelial odontogenic tumors. J Oral Pathol Med. 2007;36:229-35.

3. Ide F, Mishima K, Yamada H, et al. Unsuspected small ameloblastoma in the alveolar bone: a collaborative study of 14 cases with discussion of their cellular sources. J Oral Pathol Med. 2008;37:221-7.

4. Ide F, Mishima K, Saito I, Kusama K. Rare peripheral odontogenic tumors: report of 5 cases and comprehensive review of the literature. Oral Surg Oral Med Oral Pathol Oral Radiol Endod. 2008;106:e22-8.

5. Abaza NA, Gold L, Lally E. Granular cell odontogenic cyst: a unicytic ameloblastoma with late recurrence as follicular ameloblastoma. J Oral Maxillofac Surg. 1989;47:168-75.

6. Furuki Y, Fujita M, Mitsugi M, Tanimoto K, Yoshiga K, Wada T. A radiographic study of recurrent unicystic ameloblastoma following marsupialization. Report of three cases. Dentomaxillofac Radiol. 1997;26:214-8.

7. Navarro CM, Principi SM, Massucato EMS, Sposto MR. Maxillary unicystic ameloblastoma. Dentomaxillofac Radiol. 2004;33:60-2.

8. Cunha EM, Fernandes AV, Versiani MA, Loyola AM. Unicystic ameloblastoma: a possible pitfall in periapical diagnosis. Int Endod J. 2005;38:334-40.

9. Coleman H, Altini M, Ali H, Doglioni C, Favia G, Maiorano E. Use of calretinin in the differential diagnosis of unicystic ameloblastomas. Histopathology. 2001;38:312-7.

10. Rick GM. Adenomatoid odontogenic tumor. Oral Maxillofac Surg Clin North Am. 2004;16:333-54.

11. Philipsen HP, Reichart PA, Siar $\mathrm{CH}$, et al. An updated clinical and epidemiological profile of the adenomatoid odontogenic tumour: a collaborative retrospective study. J Oral Pathol Med. 2007;36:383-93.

12. Fukaya M, Sato H, Umakoshi H, et al. A case report of adenoameloblastoma on the maxilla. Jpn J Oral Surg. 1971;17:155-8. (in Japanese).

13. Chuan-Xiang Z, Yan G. Adenomatoid odontogenic tumor: a report of a rare case with recurrence. J Oral Pathol Med. 2007;36:440-3.

14. de Andrade Sobrinho J, de Carvalho MB, Rapoport A, Saba LM. Odontogenic adenomatoid tumor of the mandible (adenoameloblastoma). Int Surg. 1978;63:39-42.
15. Evans BL, Carr RF, Phillipe LJ. Adenoid ameloblastoma with dentinoid: a case report. Oral Surg Oral Med Oral Pathol Oral Radiol Endod. 2004;98:583-8.

16. Waldron CA. The importance of histologic study of the various radiolucent areas of the jaws. Oral Surg Oral Med Oral Pathol. 1959;12:19-30.

17. Thoma KH. Oral surgery, vol. 2. 5th ed. Saint Louis: The CV Mosby Company; 1969. p. 1007-9.

18. Meyer I, Giunta JL. Adenomatoid odontogenic tumor (adenoameloblastoma): report of case. J Oral Surg. 1974;32:448-51.

19. Nomura M, Tanimoto K, Takata T, Shimosato T. Mandibular adenomatoid odontogenic tumor with unusual clinicopathologic features. J Oral Maxillofac Surg. 1992;50:282-5.

20. Alaeddini M, Estemad-Moghadam S, Baghaii F. Comparative expression of calretinin in selected odontogenic tumours: a possible relationship to histogenesis. Histopathology. 2008;52:299-304.

21. Goldblatt LI, Brannon RB, Ellis GL. Squamous odontogenic tumor. Report of five cases and review of the literature. Oral Surg Oral Med Oral Pathol. 1982;54:187-96.

22. Anneroth G, Hansen LS. Variations in keratinizing odontogenic cysts and tumors. Oral Surg Oral Med Oral Pathol. 1982;54:530 46.

23. Warter A, Walter P, Meyer C, Barriere P, Galatir L, Wilk A. Mandibular pseudocarcinomatous hyperplasia. Histopathology. 2000;37:115-7.

24. Slater LJ. Squamous odontogenic tumor versus pseudoepitheliomatous hyperplasia. J Oral Maxillofac Surg. 2004;62:1177.

25. Naudi KB, Critchlow HA, Hunter KD. Keratoacanthoma of the gingiva - a pathological conundrum. Oral Oncol. 2009;45:e9-10.

26. Woo VL, Kelsch RD, Su L, Kim T, Zegarelli DJ. Gingival squamous cell carcinoma in adolescence. Oral Surg Oral Med Oral Pathol Oral Radiol Endod. 2009;107:92-9.

27. Pullon PA, Shafer WG, Elzay RP, Kerr DA, Corio RL. Squamous odontogenic tumor. Report of six cases of a previously undescribed lesion. Oral Surg Oral Med Oral Pathol. 1975;40:616-30.

28. Monteil RA, Terestri P. Squamous odontogenic tumor related to an unerupted lower canine. J Oral Maxillofac Surg. 1985;43:888-95.

29. Cillo JE, Ellis E, Kessler HP. Pericoronal squamous odontogenic tumor associated with an impacted mandibular third molar: a case report. J Oral Maxillofac Surg. 2005;63:413-6.

30. Krithika C, Vardhan H, Saraswathy K, Koteeswaran D, Sivapathasundaram B. Radiolucency in the anterior maxilla associated with an impacted tooth. Oral Surg Oral Med Oral Pathol Oral Radiol Endod. 2007;103:164-8.

31. Ide F, Mishima K, Saito I. Solid-cystic tumor variant of odontogenic keratocyst: an aggressive but benign lesion simulating keratoameloblastoma. Virchows Arch. 2003;442:501-3.

32. Daley TD, Multari J, Darling MR. A case report of a solid keratocystic odontogenic tumor: is it the missing link? Oral Surg Oral Med Oral Pathol Oral Radiol Endod. 2007;103:512-5.

33. Doyle JL, Grodjesk JE, Dolinsky HB, Rafel SS. Squamous odontogenic tumor: report of three cases. J Oral Surg. 1977;35:994-6.

34. Whitt JC, Dunlap CL, Sheets JL, Thompson ML. Keratoameloblastoma: a tumor sui generis or a chimera? Oral Surg Oral Med Oral Pathol Oral Radiol Endod. 2007;104:368-76.

35. Thoma KH. Carcinoma of the mandible. Am J Orthod Oral Surg. 1938;24:995-9.

36. Olson JW, Miller RL, Kushner GM, Vest TM. Odontogenic carcinoma occurring in a dentigerous cyst: case report and clinical management. J Periodontol. 2000;71:1365-70.

37. Shimoyama T, Ide F, Horie N, et al. Primary intraosseous carcinoma associated with impacted third molar of the mandible: review of the literature and report of a new case. J Oral Sci. 2001;43:287-92. 
38. Elo JA, Slater LJ, Herford AS, Tanaka WK, King BJ, Moretta CM. Squamous cell carcinoma radiographically resembling a dentigerous cyst: report of a case. J Oral Maxillofac Surg. 2007;65:2559-62.

39. Koutlas IG, Allen CM, Warnock GR, Manivel JC. Sclerosing odontogenic carcinoma: a previously unreported variant of a locally aggressive odontogenic neoplasm without apparent metastatic potential. Am J Surg Pathol. 2008;32:1613-9.
40. Sawyer DR, Nwoku AL, Mosadomi A, Kekere-Ekun AT. Odontogenic carcinoma with dentinoid. Int J Oral Maxillofac Surg. 1986;15:105-7.

41. Punnya A, Kumar GS, Rekha K, Vandana R. Primary intraosseous odontogenic carcinoma with osteoid/dentinoid formation. J Oral Pathol Med. 2004;33:121-4. 